\title{
Duas espécies novas de Polygala L. (Polygalaceae) PARA O BRASIL
}

\author{
Maria do Carmo Mendes Marques ${ }^{1}$ \& José Floriano Barêa Pastore ${ }^{2}$
}

\begin{abstract}
Resumo
(Duas espécies novas de Polygala L. (Polygalaceae) para o Brasil) O subgênero Polygala é caracterizado dentro do gênero Polygala, sobretudo, por apresentar flores com carena cristada. Ele engloba, em território brasileiro 88 espécies e 22 variedades. Polygala abreui Marques \& J.Pastore e Polygala ceciliana Marques \& J.Pastore pertencem a este subgênero e aqui são descritas, ilustradas e dadas suas distribuições geográficas: para a primeira, o Distrito Federal e os estados de Goiás e Minas Gerais e, para segunda, o Distrito Federal e Goiás. Palavras-chave: Taxonomia, Polygalaceae, Polygala, novos táxons.
\end{abstract}

\section{Abstract}

(Two new species of Polygala L. (Polygalaceae) in Brazil) The subgenus Polygala is included in the genus Polygala L., specially for presenting flowers with crested keel. It includes in Brazilian territory 88 species and 22 varieties. Polygala abreui Marques \& J.Pastore and Polygala ceciliana Marques \& J.Pastore belong to this subgenus and here they are described, illustrated and given their geographical distributions: for the first the Distrito Federal and the states of Goias and Minas Gerais and, for the second, the Distrito Federal and the state of Goias.

Key-words: Taxonomy, Polygalaceae, Polygala, new taxa.

\section{INTRODUÇÃo}

O gênero Polygala é distinto dos demais da família Polygalaceae pela inflorescência em racemos simples, flores zigomorfas e fruto cápsula rimosa. Na flora brasileira conta-se atualmente com 140 táxons (110 espécies e 30 variedades). Polygala abreui e Polygala ceciliana pertencem ao subgênero Polygala por possuírem flores com carena cristada.

\section{DESCRIÇão DOS TÁXONS}

1. Polygala abreui Marques \& J. Pastore $s p$. nov. Tipo: BRASIL. DISTRITO FEDERAL: divisa com Goiás, após a 7 curvas. Região das Lages, 21.IX.2003, fl, fr, J.F.B. Pastore et al. 710 (holótipo CEN; isótipo RB). Fig. 1

Polygala abreui P. filiformis A. St.-Hil. affinis sed capsula minore 1,7-2,2 × 0,7$0,8 \mathrm{~mm}$, seminibus notabiliter trichomatibus tenuibus et minoribus, solum ultra basin idius circa 0,3 $\mathrm{mm}$ differt.

Erva $40-80 \mathrm{~cm}$ alt. Caule simples ou com 2-3 ramos partindo do tronco espessado, frequientemente, sob os racemos, tricótomoramificado, delgado, cilíndrico, estriado, áfilo, na parte inferior pubérulo, com tricomas curtoclavados, para cima glabrescente. Racemos terminais, $2-3 \mathrm{~cm}$ ou com raque desnuda até $9 \mathrm{~cm}$ compr.; raque densamente pilosa a glabrescente, com tricomas simples e aguçados; bráctea e bractéolas caducas na flor, escassamente pubérulas no dorso e ciliadas nas margens, a bráctea 1-1,2 mm compr., lanceolada, ápice agudo a atenuado, duas a três vezes maior que as bractéolas lineares. Botão floral arredondado no ápice. Flores roxas, membranáceas; pedicelo $0,3-0,4 \mathrm{~mm}$ compr., glabro; sépalas externas superiores 1,2-1,4 $\times$ $0,6-0,7 \mathrm{~mm}$, ovadas estreitas, a inferior $1,4 \times$ $1,1 \mathrm{~mm}$, largo-ovada ou elíptica; sépalas internas 2-2,4 × 1-1,4 mm, obovadas ou elípticas, não ungüiculadas na base, ápice obtuso a arredondado, não ciliadas, com três nervuras partindo da base, bifurcadas para o ápice, menores que a corola; carena cristada, incluindo a crista 2,4-2,7 mm compr.; crista com dois lobos laterais externos e dois centrais

Artigo recebido em 05/2005. Aceito para publicação em 12/2005.

${ }^{1}$ Pesquisadora titular do Instituto de Pesquisas Jardim Botânico do Rio de Janeiro. Rua Pacheco Leão 915. CEP: 22460030. Rio de Janeiro. mmarques@jbrj.gov.br

${ }^{2}$ Mestrando em botânica da Universidade de Brasília (UnB)/ Departamento de Botânica, UnB, Campus Darcy Ribeiro, C.P. 4457, CEP 70919-970, Brasília, DF. jfpastore@unb.br. 
internos, todos fendidos no ápice, com os lobos laterais externos abaixo do ápice da abertura do cúculo; pétalas laterais desenvolvidas 2,32,4 × 1-1,3 mm, assimetricamente estreitoovadas, alcançando ou pouco ultrapassando a carena cristada; estames 8; bainha estaminal ca. 1,2 mm; filetes livres curtíssimos, os laterais maiores e ca. 0,1 mm compr.; anteras subsésseis, deiscentes por poros apicais; ovário ca. 0,6 × 0,4 mm, largo-obovado; estilete uncinado, terminado em uma cavidade cimbiforme, cuja a extremidade superior leva um apêndice bem evidente com mecha de tricomas abundantes e a inferior, um estigma globoso apoiado por um curto suporte. Cápsula 1,7-2,2 × 0,7-0,8 mm, suboblonga, não alada, maior que as sépalas internas ou, raro, do mesmo comprimento (leg. Hatschbach 29828); sementes 1,2-1,6 × 0,3-0,4 mm, estreitoovadas, não apendiculadas, revestidas de tricomas seríceos, finos e brilhantes, eretos, ultrapassando ca. 0,3 mm o comprimento da mesma, endosperma presente; embrião ca. 0,5 mm, contínuo.

Parátipos: BRASIL. DISTRITO FEDERAL: Brasília, Poço Azul, 22.I.2003, fl. fr., J. F. B. Pastore et al. 266 (RB); Chapada da Contagem, VI.2004, fl. fr., J. F. B. Pastore et al. 924 (CEN); área de proteção ambiental do Gama-Cabeça de Veado, Fazenda Água Limpa, 25.IX.2002, fl. fr., R. C. Mendonça et al.5078 (IBGE, RB); Chapada da Contagem, 3.VI.2004, fl. fr., J. F. B. Pastore et al. 924 (CEN); Rodovia BR 060, km 20, 17.II.1975, fl. fr., G. Hatschbach et al. 36221 (MBM, $\mathrm{RB})$; GOIÁS, Crominia, próximo à mina de cromita que dista $5 \mathrm{~km}$ da cidade de Cromita, 14.IV.1988, fl. fr., J. A. Rizzo et al. 10594 (UFG); Cavalcante, caminho para cachoeira Santa Bárbara, 7.III.2003, fl. fr., J. F. B. Pastore 376 (CEN, RB); MINAS GERAIS: Belo Horizonte, Serra do Curral, 19.III.1925, fl. fr., A. Chase 8932 (US).

Polygala filiformis A. St.-Hil. táxon mais afim de Polygala abreui devido ao caule delgado, cilíndrico, estriado e áfilo, como também por apresentar sementes não apendiculadas, apresenta porém, cápsula cerca de 3,6 mm compr. e sementes dotadas de longos tricomas, espessos e mais ou menos do mesmo comprimento desde o ápice e ultrapassam a base da semente acima de $1 \mathrm{~mm}$.

Espécie nova restrita, até o momento, ao Distrito Federal e aos estados de Goiás e Minas Gerais, foi encontrada em altitudes de 8001.155 m s.m., em campos rupestres e campos cerrados, úmidos ou secos. Flores e frutos foram verificados nos meses de janeiro, março, abril, setembro e novembro.

Polygala abreui é dedicada ao engenheiro Dr. Carlos Henrique Abreu Mendes, na época Secretário do Meio Ambiente do Estado do Rio de Janeiro, pelo incentivo à realização do projeto "Mapeamento da Cobertura Vegetal, Listagem das Espécies e Flórula da Área de Proteção Ambiental de Cairuçu, Município de Parati, RJ".

2. Polygala ceciliana Marques \& J. Pastore sp. nov. Tipo: BRASIL. DISTRITO FEDERAL: Brasília, Barragem do Descoberto, II.2004, J.F.B. Pastore et al. 872 (holótipo RB; isótipo CEN).

Fig. 1

Species nova P. tenuis DC. affinis habitu herbaceo autem foliis basalibus, forma carina et semine appendiculato toto coelo differt; P. ceciliana P. atropurpurea $A$. St.-Hil. var. atropurpurea etiam affinis floribus croceo-glandulosis, semine elliptico-globoso breviter appendiculato sed habitu herbaceo, floribus albicantibus et corolla caduca in fructu differt.

Erva 10-20 cm alt. Raiz tênue, geralmente, bifurcada. Caule ereto, simples ou raramente ramificado, filiforme-anguloso, estriado, com tricomas curto-clavados na porção basal, para o ápice glabro, subáfilo. Folhas basais, verticiladas, pecioladas, desiguais, 6-2,5 × 1,2-2 mm, obovadas e elípticas, as restantes alternas, distantes, 5-7 $\times 0,5-0,7 \mathrm{~mm}$, subsésseis a sésseis, lineares a aciculares, pontuadas de glândulas cróceas, membranáceas. Racemos terminais, 5-25 mm compr., raque salpicada de glândulas cróceas; 


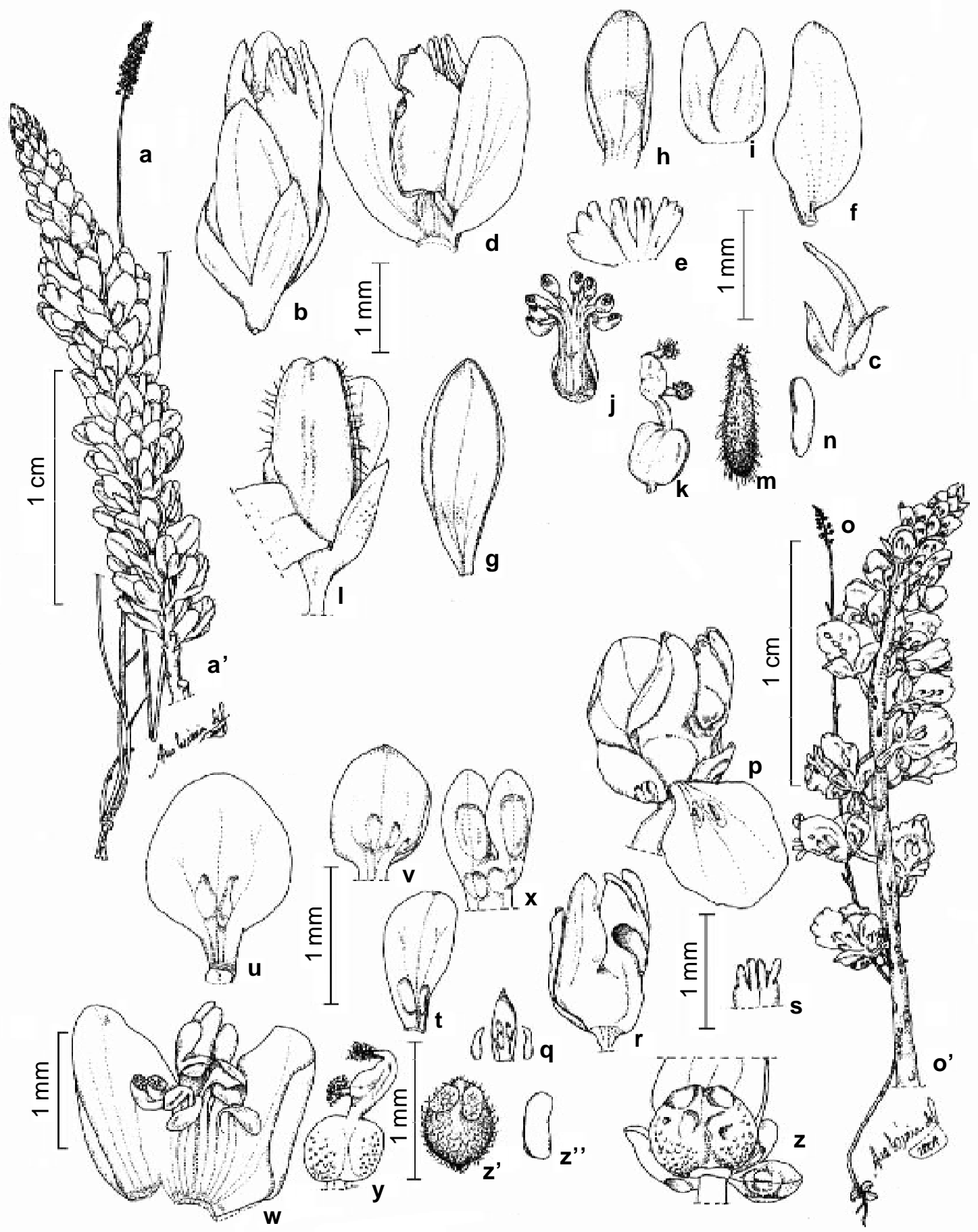

Figura 1 - Polygala abreui. a- hábito; a'- inflorescência; b- flor; c- bráctea e bractéolas; d- corola; e- crista da carena; f- uma das pétalas laterais desenvolvidas; g- uma das sépalas internas; h- sépala inferior; i- sépalas superiores; j- androceu; k- gineceu; l- fruto com as sépalas persistentes; m- semente; n- embrião. (Pastore 710). Polygala ceciliana. o- hábito; o'- inflorescência; p- flor; q- bráctea e bractéolas; r- corola; s- crista da carena; t- uma das pétalas laterais desenvolvidas; u- uma das sépalas internas; $\mathrm{v}$ - sépala inferior; $\mathrm{x}$ - sépalas superiores; $\mathrm{w}$ - androceu com as pétalas laterais desenvolvidas presas ao dorso; y- gineceu; z- fruto com as sépalas persistentes; z'- semente; z”- embrião. (Pastore 872). 
bráctea e bractéolas caducas na flor, a bráctea, 0,5-0,6 ×0,2 mm, lanceolada, aguda no ápice, membranácea, três vezes maior que as laterais diáfanas. Botão floral arredondado no ápice. Flores esbranquiçadas, pontuadas de glândulas cróceas, membranáceas; pedicelo 0,4-0,5 mm compr., glabro; sépalas externas superiores ca. $0,6 \times 0,3 \mathrm{~mm}$, estreito-ovadas; a inferior ca. $0,8 \times 0,6 \mathrm{~mm}$, largo-ovada; sépalas internas 1-1,2 × 0,8 mm, largo-obovadas ou elípticas, curto-ungüiculadas, ápice obtuso a arredondado, não ciliadas, com três nervuras partindo da base, bifurcadas para o ápice, alcançando ou pouco superando a carena cristada. Carena ca. $1 \mathrm{~mm}$ compr., o cúculo alargando-se paulatinamente e obliquamente para o ápice da abertura e a crista 4-6 lobos, menos de 0,05 mm compr.; pétalas laterais desenvolvidas 1$1,2 \mathrm{~mm} \times 0,7-0,8 \mathrm{~mm}$, assimetricamente obovadas, alcançando ou pouco superando a carena cristada; estames 8 , bainha estaminal ca. 0,6 mm compr., filetes livres laterais e centrais mais longos, 0,2-0,3 mm compr.; anteras deiscentes por poros apicais; ovário ca. $0,3 \times 0,25 \mathrm{~mm}$, suborbicular, pontuado de glândulas cróceas; estilete uncinado, terminado por uma cavidade cimbiforme, cuja a extremidade superior leva um apêndice bem evidente com uma mecha de tricomas abundantes e a inferior um estigma globoso apoiado por um curto suporte. Cápsula 0,6$0,7 \times 0,7-0,9 \mathrm{~mm}$, orbicular a oblata, não alada, pontuada de glândulas cróceas, alcançando a metade das sépalas internas; sementes ca. 0,6 $\times 0,5 \mathrm{~mm}$, largo-ovadas, laxamente pubérulas a glabriúsculas, apendiculadas; apêndices pequenos, ca. 0,2 mm compr.; endosperma presente, embrião ca. $0,5 \mathrm{~mm}$, contínuo.

Parátipos: BRASIL. DISTRITO FEDERAL: Brazilândia, II.2003, fl. fr., J. F. B. Pastore et al. 369 (CEN); Fazenda Água Limpa, Mirante, próximo à rodovia, I.2003, fl. fr., $J$. F. B. Pastore et al. 316 (CEN, RB); Brasília, bacia do rio S. Bartolomeu, 3.III.1980, fl. fr., E. P. Heringer et al. 3626 (IBGE); área do
Cristo Redentor, 14.II.1990, fl. fr., M. Pereira et al. 587 (IBGE); GOIÁS: Cavalcante, Comunidade Kalunga, caminho para a cachoeira Santa Bárbara, 26.II.2005, fl. fr., J. F. B. Pastore \& M. Aquino 1272 (CEN).

Polygala tenuis DC. afim de Polygala ceciliana pelo hábito herbáceo e, exceto as basais, pelas folhas lineares e distantes, porém difere desta devido ao cúculo da carena largo na base e paulatinamente estreitando-se para o ápice, como também por apresentar poucas glândulas apenas na base das sépalas externas.

Polygala atropurpurea A. St. Hil. var. atropurpurea também é afim de Polygala ceciliana devido às flores densamente cróceoglandulosas, semente elíptico-globosa brevemente apendiculada, porém apresenta flores atropurpúreas e corola persistente no fruto.

Espécie até o momento endêmica do Distrito Federal e Goiás, encontrada em campos úmidos, com solos ricos em matéria orgânica e em época de chuvas frequientes. Flores e frutos registrados para os meses de janeiro e fevereiro.

P. ceciliana é uma justa homenagem à amiga Dra. Cecília Gonçalves Costa, pesquisadora do Instituto de Pesquisas do Jardim Botânico do Rio de Janeiro e orientadora de grande destaque no ramo da Anatomia Vegetal.

\section{REFERÊNCIAS BIBLIOGRÁFICAS:}

Chodat, R. 1893. Monografia Polygalacearum. Mémoire de la Societé de Physique et D'Histoire Naturelle Genève. 31(2): 1-500, est.13-35.

Marques, M. C. M. 1979. Revisão das espécies do gênero Polygala L. (Polygalaceae) do Estado do Rio de Janeiro. Rodriguésia 31 (48): 69-339, est.1-84.

1988. Polígalas do Brasil V Seção Polygala (Polygalaceae). Arquivos do Jardim Botânico do Rio de Janeiro 29: 1114, 11 tabs. 
